\title{
Numerical Analysis of Dual Band Mirrored-F Antenna for WLAN and Mobile WiMAX Applications
}

\author{
Md. Juwel Rana \\ Dept. of EEE \\ Daffodil International University, \\ Dhaka, Bangladesh
}

\author{
Md. Saiful Islam \\ Dept. of EEE \\ Prime University, \\ Dhaka, Bangladesh
}

\begin{abstract}
The numerical simulation of a low-profile dual band mirrored$\mathrm{F}$ antenna for $3.5 / 5.5 \mathrm{GHz}$ WiMAX and $5.2 \mathrm{GHz}$ WLAN applications is proposed. It has a dimension of $29 \times 14.5 \mathrm{~mm}^{2}$ and the two resonant modes of the antenna provide bandwidth of $13.8 \%(3.35 \mathrm{GHz}-3.85 \mathrm{GHz})$ and $17.4 \%$ (4.9 GHz-5.85 $\mathrm{GHz}$ ) with maximum gain of 3.36 and $7.35 \mathrm{dBi}$ respectively. The peak values of return loss are -22.124 and $-52.282 \mathrm{~dB}$ and VSWR varies between 1.83 1.17 and 1.004 1.9 at the lower and upper resonant frequency bands. In addition, the antenna also provides almost omnidirectional radiation characteristics and excellent impedance matching.
\end{abstract}

\section{Keywords}

Mirrored-F antenna, WiMAX, WLAN, Method of Moments (MoM), Numerical Electromagnetic Code (NEC).

\section{INTRODUCTION}

Wireless communication has brought a revolutionary change in modern communication technology. It has experienced tremendous growth in the last decade, resulting in more and more ubiquitous communications. Today wireless communication covers a very wide array of applications such as wireless local area network (WLAN), worldwide interoperability for microwave access (WiMAX), other wireless local loop (WLL) and a variety of satellite systems. The demand of WLANs are increasing numerously worldwide, because they provide high speed connectivity and easy access to networks without wiring also in recent times of WiMAX, which can provide a long operating range with a high data rate for mobile broadband wireless access, faultless internet access for wireless users becomes more popular. The rapid growing WLAN operating bands are IEEE $802.11 \mathrm{~b} / \mathrm{a} / \mathrm{g}$ at $2.4 \mathrm{GHz}(2400-2484 \mathrm{MHz}), 5.2 \mathrm{GHz}(5150-5350 \mathrm{MHz})$ and $5.8 \mathrm{GHz}(5725-5825 \mathrm{MHz})$ also the bands of WiMAX operation in the $2.5 \mathrm{GHz}$ band (2500-2690 MHz), $3.5 \mathrm{GHz}$ band $(3300-3700 \mathrm{MHz})$ and $5.5 \mathrm{GHz}$ band $(5250-5850 \mathrm{MHz})$ [1].

To cope up with the widespread modern wireless communication application urges on the need of dual band or multiband antennas including attractive features like ease of fabrication, low cost, omnidirectional radiation characteristics and little or no maintenance. Recently, the design of dual band or multiband antennas has received the attention of antenna researchers like A Compact Loop Type Antenna for Bluetooth, S-DMB, Wibro, WiMax, and WLAN Applications [2], A Compact Tri-Band PIFA Antenna for $2380-2550 \mathrm{MHz}$ and 4810-5560 MHz WLAN and WiMAX Applications [3],

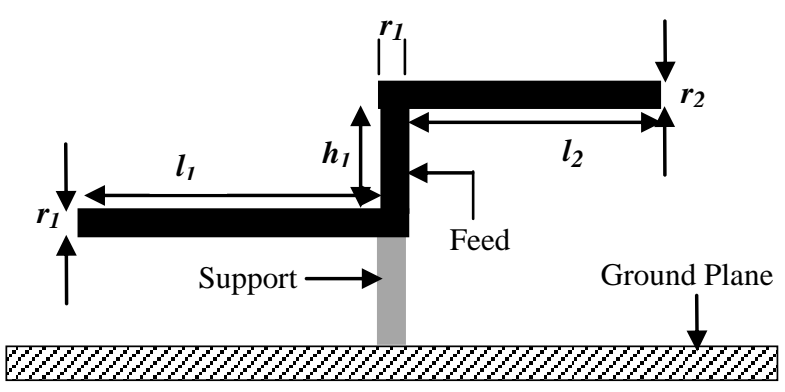

Figure 1: S-shaped antenna

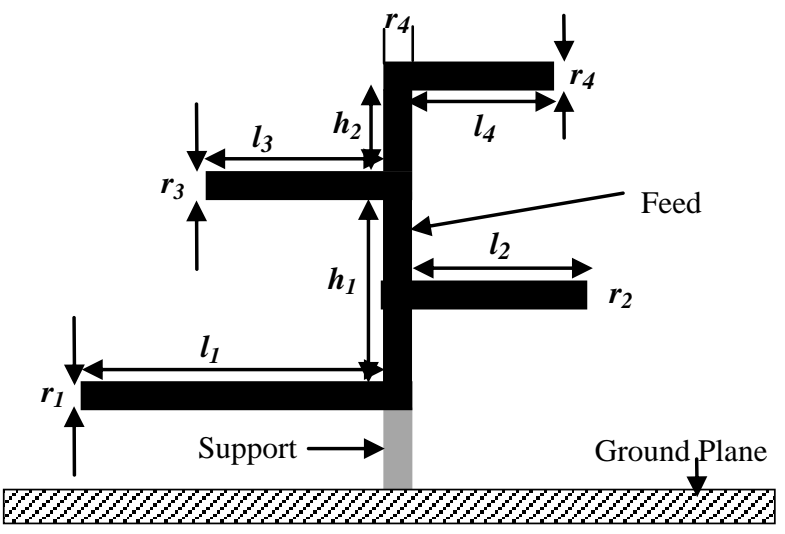

Figure 2: Mirrored F-antenna

A Printed Multiband Antenna operating at 2.4/3.5/5.2/5.5/5.8 $\mathrm{GHz}$ for Cellphone Applications [4], Capacitively Fed Hybrid Monopole/Slot Chip Antenna for $2.5 / 3.5 / 5.5 \mathrm{GHz}$ WiMAX Operation in the Mobile Phone [5], Dual Wideband Printed Monopole Antenna for WLAN/WiMAX Applications [6], Internal Composite Monopole Antenna for 2500-2690/34003600/5250-5850 MHz WLAN/WiMAX Operation in a Laptop Computer [7], Multiband CPW-Fed Triangle-Shaped Monopole antenna for $2.4 / 3.4 / 5 \mathrm{GHz}$ Wireless Applications [8] have been reported.

This paper proposes the simulation of a low profile, dual band and high forward gain performance for realizing $3.5 / 5.5 \mathrm{GHz}$ WiMAX and $5.2 \mathrm{GHz}$ WLAN applications using Method of Moments (MoM) in Numerical Electromagnetics Code (NEC). 
Table 1. Dimension of proposed antennas

\begin{tabular}{|c|c|c|c|}
\hline Antenna & Parameter & Length $(\mathrm{mm})$ & Dimension \\
\hline \multirow{5}{*}{$\begin{array}{l}\text { S-shaped } \\
\text { antenna }\end{array}$} & $l_{1}$ & 14 & \multirow{5}{*}{$\begin{array}{l}24 \times 3 \\
\left(\mathrm{~mm}^{2}\right)\end{array}$} \\
\hline & $l_{2}$ & 10 & \\
\hline & $h_{1}$ & 3 & \\
\hline & $r_{1}$ & 1.05 & \\
\hline & $r_{2}$ & 1 & \\
\hline \multirow{10}{*}{$\begin{array}{l}\text { Mirrored } \\
\text { F-antenna }\end{array}$} & $l_{1}$ & 18.5 & \multirow{10}{*}{$\begin{array}{c}29 \times 14.5 \\
\left(\mathrm{~mm}^{2}\right)\end{array}$} \\
\hline & $l_{2}$ & 10.5 & \\
\hline & $l_{3}$ & 10 & \\
\hline & $l_{4}$ & 8 & \\
\hline & $h_{1}$ & 9.5 & \\
\hline & $h_{2}$ & 5 & \\
\hline & $r_{1}$ & 1.05 & \\
\hline & $r_{2}$ & 0.5 & \\
\hline & $r_{3}$ & 1.1 & \\
\hline & $r_{4}$ & 1 & \\
\hline
\end{tabular}

\section{ANTENNA DESIGN}

In designing the mirrored F-antenna to provide the applications of WLAN and WiMAX with high gain, better performance and simple structure, we studied different types of shapes and lengths using Method of Moments (MoM) in NEC. We conducted our study in a trial and error basis to be ascertain of the effect of different loading on the antenna performance to find out the optimal design. Initially an Sshaped antenna which has a dimension of $24 \times 3 \mathrm{~mm}^{2}$, is selected as prototype and its characteristics is simulated in NEC. But, in search of a dual band characteristics, the Sshaped antenna is modified by loading it with a similar shape placed on top of it, together giving it a mirrored F-shape. The proposed antenna has a size of $29 \times 14.5 \mathrm{~mm}^{2}$. Figure 1 shows the geometry of the primary design of S-shaped antenna while Figure 2 shows the actual antenna geometry of mirrored-F antenna. The antenna is assumed to feed by $50 \Omega$ coaxial connector, with its central conductor connected to the feeding point and its outer conductor soldered to the ground plane. The dimension of the ground plane considered as $60 \mathrm{~mm} \times 60$ $\mathrm{mm}$. The lengths and diameters of the antenna as given in Table 1 are so chosen so as to provide the applications of WLAN and mobile WiMAX with high gain, good impedance matching and omnidirectional radiation pattern.

\section{SIMULATION RESULT}

The proposed antennas are constructed and numerically analyzed using NEC simulator. Figure 3 shows the simulated frequency responses of return loss for the proposed design. Both the antennas provide appreciable return loss in the respective frequency bands than the commonly required level of $-10 \mathrm{~dB}$. As it is seen, the S-shaped antenna offers only a single band covering a bandwidth of $1500 \mathrm{MHz}$ (4.76-6.26 $\mathrm{GHz}$ ) resonating at $5.26 \mathrm{GHz}$. But the mirrored F-antenna (modified S-shape) offers two distinct resonant frequencies at $3.6 \mathrm{GHz}$ and $2.45 \mathrm{GHz}$, respectively. It is then further modified to get an optimized structure which would offer a better frequency band characteristics. This is shown in Figure 4. The peak values of return loss is $-44.126 \mathrm{~dB}$ for S-shaped
Table 2. Characteristics of the proposed antennas

\begin{tabular}{|c|c|c|c|c|}
\hline Antenna & $\begin{array}{c}\text { Frequency } \\
(\mathbf{G H z})\end{array}$ & $\begin{array}{c}\text { Band } \\
(\mathbf{G H z})\end{array}$ & $\begin{array}{c}\text { Bandwidth } \\
(\mathbf{M H z})\end{array}$ & $\begin{array}{c}\text { Gain } \\
(\mathbf{d B i})\end{array}$ \\
\hline $\begin{array}{c}\text { S-shaped } \\
\text { antenna }\end{array}$ & 5.26 & $\begin{array}{c}4.76- \\
6.26\end{array}$ & $\begin{array}{c}1500 \\
(28.5 \%)\end{array}$ & 8.9 \\
\hline \multirow{2}{*}{$\begin{array}{c}\text { Mirrored } \\
\text { F-antenna }\end{array}$} & 3.6 & $\begin{array}{c}3.35- \\
3.85\end{array}$ & $\begin{array}{c}500 \\
(13.8 \%)\end{array}$ & 3.36 \\
\cline { 2 - 5 } & 5.45 & $\begin{array}{c}4.9- \\
5.85\end{array}$ & $\begin{array}{c}950 \\
(17.4 \%)\end{array}$ & 7.35 \\
\hline
\end{tabular}

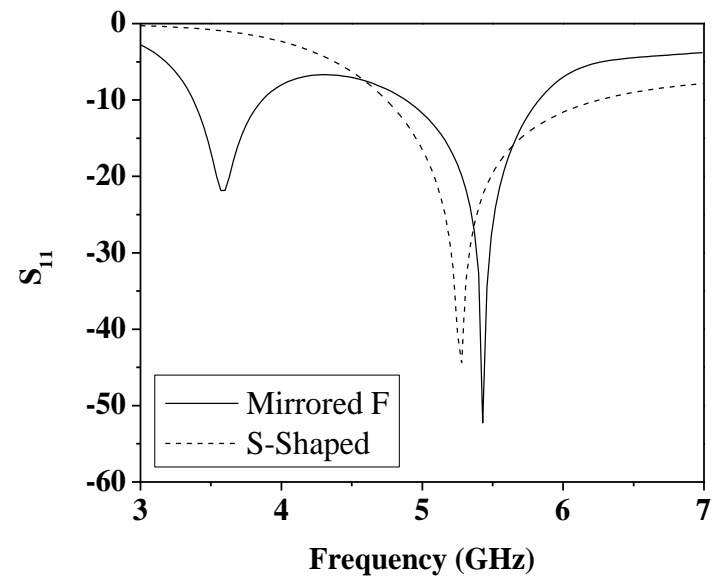

Figure 3: Return loss variation of the proposed antennas

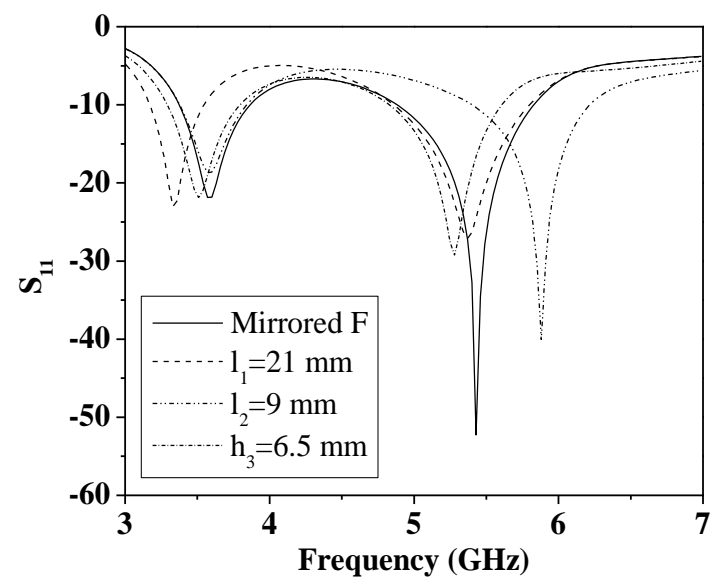

Figure 4: Return loss variation with length of F-antenna

antenna and -22.124 and $-52.282 \mathrm{~dB}$ for mirrored F-antenna. The relative characteristics of the proposed antennas are also summarized in Table 2.

The variation in voltage standing wave ratio (VSWR) as a function of frequency for S-shaped and mirrored F-shaped antenna is shown in Figure 4. At resonant frequency we obtain VSWR as 1.0093 for S-shaped and 1.169 and 1.004 for F-shaped antenna. The value of VSWR is near about 1 and its variation within the operating band is very small. In a same fashion other characteristics for the both shapes are compared graphically (illustrated from Figure 5 to 8 ) for a better understanding. The input impedance for both antennas is obtained as 49.566 and $50.03 \Omega$ and variation within the bandwidth is very small. The phase shift decreases in the mirrored F-shaped antenna. It is due to the application of load to the S-shaped antenna. The S-shaped antenna has a forward 


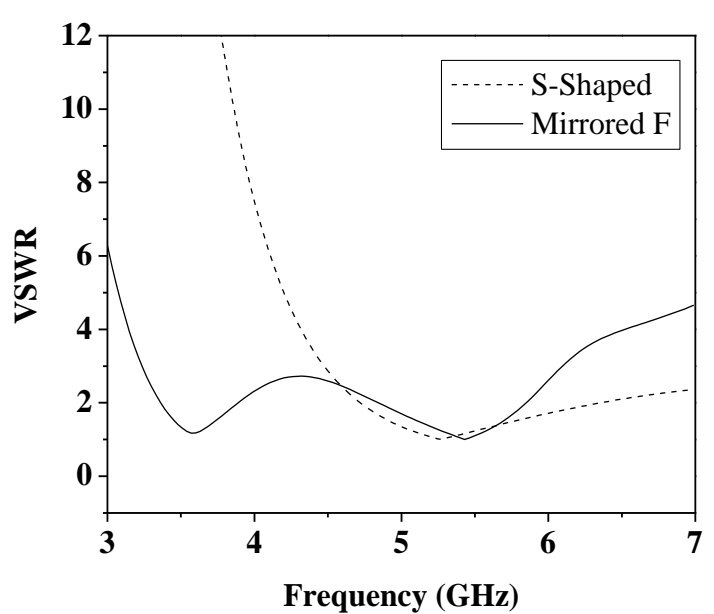

Figure 5: Variation of VSWR with frequency of proposed antenna

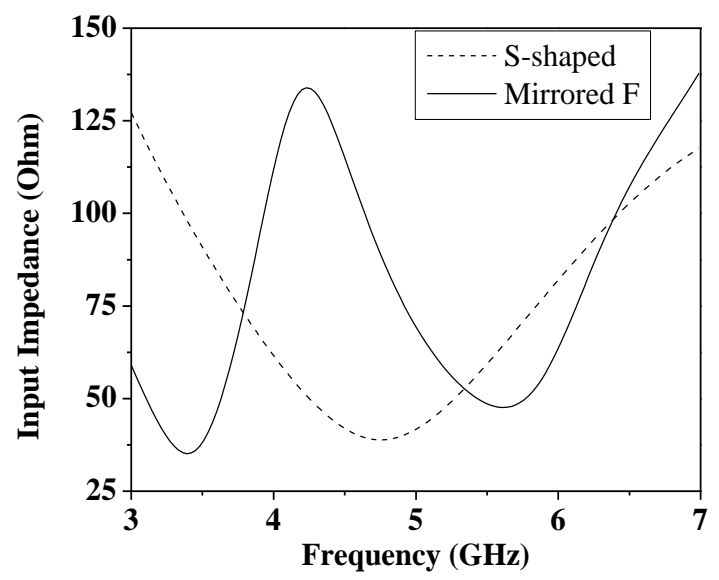

Figure 6: Impedance variation of the proposed antennas

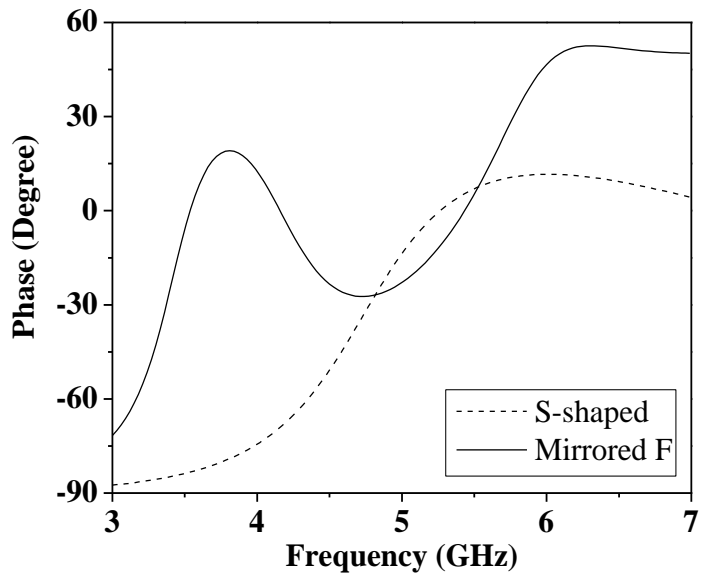

Figure 7: Phase variation of the proposed antennas

gain of $8.9 \mathrm{dBi}$ while the F-shaped antenna has 3.36 and 7.35 $\mathrm{dBi}$ in the operating bandwidth. From the compared gain characteristics, the S-shaped antenna has a better gain (8.9 $\mathrm{dBi}$ ) than the mirrored $\mathrm{F}$ antenna $(7.35 \mathrm{dBi})$ has. Peak gain comparison with the proposed antenna and reference antenna for mobile WiMAX, Wi-Fi, WLAN and Bluetooth application are listed in Table 3. From the comparison table, proposed mirrored $\mathrm{F}$ antenna has much higher gain than the antenna have been proposed for mobile WiMAX, WLAN and Wi-Fi operation. Figure 9 shows the normalized radiation patterns

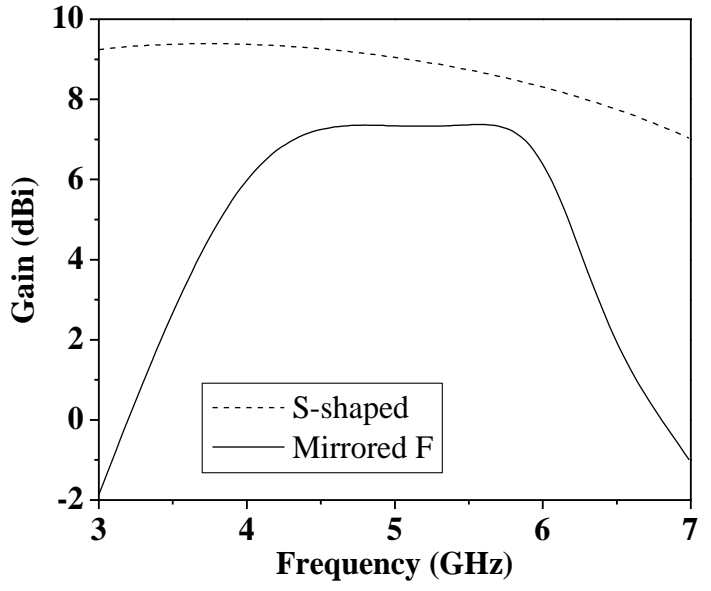

Figure 8: Total gain of the proposed antennas with frequency

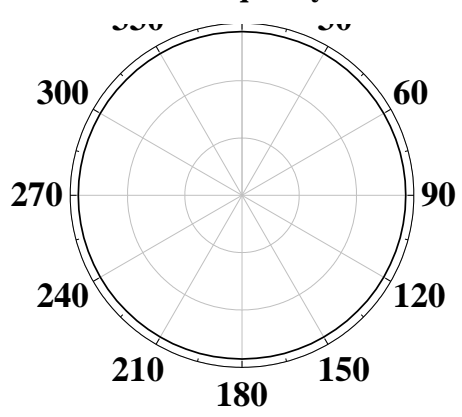

(a)

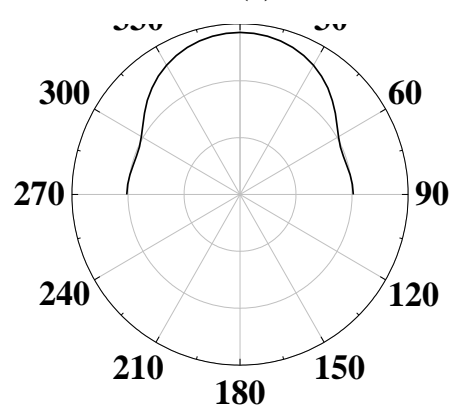

(b)

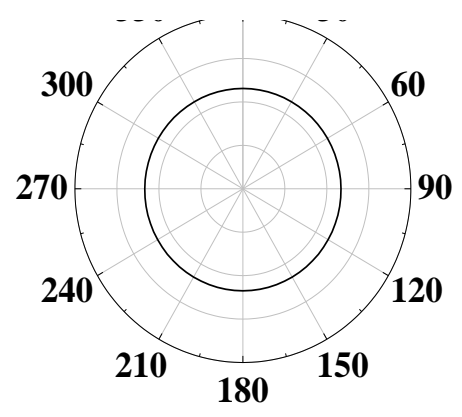

(c) 


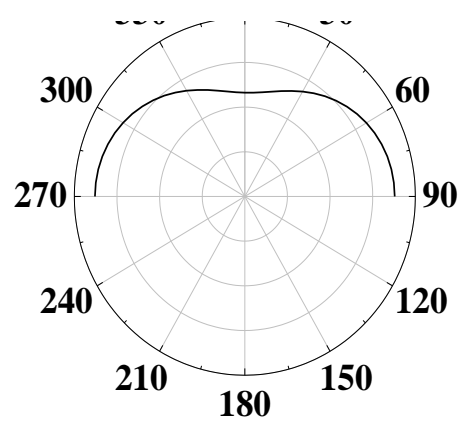

(d)

Figure 9: Radiation pattern of S-shaped antenna (a) total gain in horizontal plane (b) total gain in vertical plane and mirrored F-antenna (c) total gain in horizontal plane (d) total gain in vertical plane.

Table 3. Comparison between existing antenna and our proposed antenna

\begin{tabular}{|c|c|c|c|c|}
\hline \multirow[b]{2}{*}{ Antenna } & \multicolumn{4}{|c|}{ Gain (dBi) } \\
\hline & $\begin{array}{l}\text { 3.5 GHz } \\
\text { WiMAX }\end{array}$ & $\begin{array}{c}5.2 \\
\text { GHz } \\
\text { WLAN } \\
\end{array}$ & $\begin{array}{l}5.5 \mathrm{GHz} \\
\text { WiMAX }\end{array}$ & $\begin{array}{c}5.8 \\
\text { GHz } \\
\text { WLAN } \\
\end{array}$ \\
\hline $\begin{array}{c}\text { S-shaped } \\
\text { Antenna } \\
\text { (Proposed) }\end{array}$ & - & 8.93 & 8.73 & 8.5 \\
\hline $\begin{array}{l}\text { Mirrored F- } \\
\text { antenna } \\
\text { (Proposed) }\end{array}$ & 3.36 & 7.33 & 7.36 & 7.22 \\
\hline $\begin{array}{c}\text { Compact } \\
\text { Loop Type } \\
\text { Antenna [2] }\end{array}$ & - & & 6.41 & \\
\hline $\begin{array}{c}\text { Compact } \\
\text { Tri-Band } \\
\text { PIFA } \\
\text { Antenna [3] }\end{array}$ & - & 2.3 & - & 4.4 \\
\hline $\begin{array}{c}\text { Printed } \\
\text { Multiband } \\
\text { Antenna [4] }\end{array}$ & 0.78 & 1.6 & 3.07 & 1.49 \\
\hline $\begin{array}{c}\text { Capacitively } \\
\text { Fed Hybrid } \\
\text { Chip } \\
\text { Antenna [5] }\end{array}$ & $2.6-4.6$ & - & $2.7-5.8$ & - \\
\hline $\begin{array}{l}\text { Wideband } \\
\text { Printed } \\
\text { Monopole } \\
\text { Antenna [6] }\end{array}$ & 2.1 & - & 2 & \\
\hline $\begin{array}{l}\text { Composite } \\
\text { Monopole } \\
\text { Antenna [7] }\end{array}$ & $3.2-3.7$ & & $4.6-5.3$ & \\
\hline $\begin{array}{l}\text { Triangle- } \\
\text { Shaped } \\
\text { Monopole } \\
\text { antenna [8] }\end{array}$ & 2.54 & 3.59 & - & 3.05 \\
\hline
\end{tabular}

for the resonant frequency are shown as total gain in vertical (YZ/XZ plane) and horizontal plane (XY plane). The antenna's normalized total radiation in vertical and horizontal plane is almost omnidirectional at the $5.2 / 5.8 \mathrm{GHz}$ WLAN and $3.5 / 5.5 \mathrm{GHz}$ WiMAX operating frequency. The proposed antennas has radiation efficiency of $100 \%$ and $93.1 \%$ respectively.

\section{CONCLUSION}

A simple structured dual frequency mirrored F-antenna have been proposed. The proposed antenna has a compact dimension of $29 \times 14.5\left(\mathrm{~mm}^{2}\right)$ and obtained operating bandwidths can cover the $5.2 \mathrm{GHz}$ WLAN band and the 3.5/5.5 GHz mobile WiMAX band. Because of its compact size, the antenna can be embedded within different portable devices that employs the applications of WLAN and WiMAX. Minimum return loss, unity VSWR, high forward gain, good impedance matching, and omnidirectional radiation characteristics of the proposed antenna reflects its efficacy in mobile and wireless communication applications.

We are currently working on the improvement of antenna gain, reducing its size and to find some sharper frequency bands.

\section{REFERENCES}

[1] L. Pazin, N. Telzhensky, and Y. Leviatan, "Multiband Flat-Plate Inverted-F Antenna for Wi- Fi/WiMAX Operation," IEEE antennas and wireless propagation letters, Vol. 7, 2008.

[2] Yong-sun Shin and Seong-Ook Park, "A Compact Loop Type Antenna for Bluetooth, S-DMB, Wibro, WiMax, and WLAN Applications", IEEE antennas and wireless propagation letters, Vol. 6, 2007.

[3] Shaoli Zuo, Yingzeng Yin, Zhiya Zhang, and Weijun $\mathrm{Wu}$, "A Compact Tri-Band PIFA Antenna for WLAN and WiMAX Applications", Microwave and Optical Technology Letters / Vol. 52, No. 4, April 2010.

[4] Shih-Ying Sun, Sheng-Yi Huang, and Jwo-Shiun Sun, "A Printed Multiband Antenna for Cellphone Applications", Microwave and Optical Technology Letters / Vol. 51, No. 3, March 2009.

[5] Peng-Yu Lai and Kin-Lu Wong, "Capacitively Fed Hybrid Monopole/Slot Chip Antenna for 2.5/3.5/5.5 GHz WiMAX Operation in the Mobile Phone", Microwave and Optical Technology Letters / Vol. 50, No. 10, October 2008.

[6] Chien-Yuan Pan, Tzyy-Sheng Horng, Wen-Shan Chen, and Chien-Hsiang Huang, "Dual Wideband Printed Monopole Antenna for WLAN/WiMAX Applications", IEEE Antennas and Wireless Propagation Letters, Vol. 6, 2007

[7] Kin-Lu Wong and Liang-Che Chou, "Internal Composite Monopole Antenna for WLAN/WiMAX Operation in a Laptop Computer", Microwave and Optical Technology Letters / Vol. 48, No. 5, May 2006.

[8] Y. Song, Y.-C. Jiao, G. Zhao, and F.-S. Zhang, "Multiband CPW-Fed Triangle-Shaped Monopole antenna for Wireless Applications", Progress In Electromagnetics Research, PIER 70, 329-336, 2007. 